\title{
IL-6/STAT3 signaling pathway regulates the proliferation and damage of intestinal epithelial cells in patients with ulcerative colitis via H3K27ac
}

\author{
YANRONG LI $^{1}$, YUJIE JIA ${ }^{2}$, TINGFANG CUI ${ }^{1}$ and JIAYUAN ZHANG $^{1}$ \\ Departments of ${ }^{1}$ Gastroenterology and ${ }^{2}$ Neurology, The First Affiliated Hospital of \\ Jinzhou Medical University, Jinzhou, Liaoning 121000, P.R. China
}

Received August 13, 2020; Accepted May 4, 2021

DOI: $10.3892 /$ etm.2021.10322

\begin{abstract}
The aim of the present study was to investigate the effect of the IL-6/STAT3 signaling pathway on intestinal epithelial barrier injury in patients with ulcerative colitis (UC). Fifty-two patients with UC and 21 healthy subjects were recruited. The expression level of IL-6 in plasma was determined by ELISA. Normal human colon mucosal epithelial NCM460 cells were treated with IL-6 or plasma from the patients with UC. Then, the transepithelial electrical resistance value, fluorescein yellow permeability and zonulin release were evaluated. Using reverse transcription-quantitative (q)PCR and western blotting, claudin (CLDN) 1 and CLDN2 expression levels were analyzed. Furthermore, western blotting was used to detect phosphorylation of STAT3. Chromatin immunoprecipitation-qPCR was performed to investigate the enrichment of $\mathrm{H} 3 \mathrm{~K} 27 \mathrm{ac}$ in the promoter regions of CLDN1 and CLDN2. The present study revealed that IL- 6 content was elevated in the plasma from patients with UC and increased with the progression of the disease. IL- 6 was also observed to induce intestinal epithelial cell barrier injury and regulate barrier function by influencing the expression of tight junction-related proteins, as well as STAT3. The IL-6/STAT3 signaling pathway regulated transcription of CLDN1 and CLDN2 by affecting the enrichment of histone H3K27ac in their promoter regions. Thus, the significantly increased expression level of IL- 6 in the peripheral blood of patients with UC indicates a positive association with the development of UC. Furthermore, the IL-6/STAT3 signaling pathway influences the function of the intestinal barrier by affecting the $\mathrm{H} 3 \mathrm{~K} 27 \mathrm{ac}$ level in intestinal epithelial cells.
\end{abstract}

Correspondence to: Dr Yanrong Li, Department of Gastroenterology, The First Affiliated Hospital of Jinzhou Medical University, No. 2, Section 5, People's Street, Guta, Jinzhou, Liaoning 121000, P.R. China

E-mail: lyr_sxr@163.com

Key words: IL-6, STAT3, ulcerative colitis, H3K27ac

\section{Introduction}

Ulcerative colitis (UC) is a common clinical gastrointestinal disease with unclear causes (1). UC is essentially a chronic non-specific inflammatory disease that invades colonic mucosa (2). It usually begins in the left half of the colon and gradually develops throughout the colon towards the proximal region $(2,3)$. Patients with UC exhibit different degrees of clinical symptoms (4). UC is mainly associated with infection, immunology, genetic and mental factors, among which the infection and immunology factors predominate $(5,6)$.

IL-6 is a multi-functional cytokine that binds to soluble IL-6 receptor (IL-6R) to form the IL-6/IL-6R protein complex, leading to activation of glycoprotein 130 on the surface of the cell membrane and the upregulated phosphorylation of STAT3 protein $(7,8)$. STAT3, a member of the STAT family, is an important downstream protein in the IL-6 signaling chain, and it has four isomers STAT3 $\alpha$, STAT3 $\beta$, STAT3 $\gamma$ and STAT3 $\varepsilon(9,10)$. STAT3 predominantly functions as a transcriptional factor and its functional structural unit is composed of seven parts: $\mathrm{N}$-terminal tetramerization domain (NH2), coiled-coil domain (CCD), DNA-binding domain (DBD), linker domain, Src homology 2 (SH2) domain, SH3 domain and C-terminal transcriptional activation domain (TAD) (11). NH2 is primarily responsible for tetramerization of STAT; CCD provides sites for protein interaction; DBD specifically binds to IFN- $\gamma$ palindrome sequence; linker domain stabilizes DBD; SH2 is involved in the formation of STAT3 dimer; and the serine in TAD activates STAT3 and regulates gene transcription (12). The IL-6/STAT3 signaling pathway is important in physiological and pathological processes, such as tumors, immune diseases and angiogenesis, presenting as important targets for clinical treatment $(13,14)$. Histone modification is an important means for regulating gene transcription, in which enrichment of $\mathrm{H} 3 \mathrm{~K} 27 \mathrm{ac}$ in the promoter region is conducive to the opening of chromatin and promotes gene transcription (15).

Intestinal epithelial cells are the basic unit of the intestinal physical barrier and absorption function (16). The small intestine of mammalians consists of villi and lacunae covered by stratified columnar epithelial cells and there are endocrine cells, goblet cells and lymphocytes among the intestinal epithelial cells (17). The ability of intestinal self-repair 
is closely associated with the proliferation and migration of intestinal epithelial cells. After injuries, intestinal epithelial cells undergo self-repair by their own proliferation and migration to the injured site (18). If the intestinal epithelial cells are seriously damaged, the self-repair of the intestinal tract becomes difficult (18). Cytokines, including IL-18, IL-10 and IL-6, have been proven to play important roles in local inflammation, repair and damage of tissues (19). However, the role of the IL-6/STAT3 signaling pathway on intestinal injury remains unclear. Thus, in the present study, the effect of the IL-6/STAT3 signaling pathway on intestinal epithelial cells was investigated at the tissue and cellular levels.

\section{Materials and methods}

Subjects. Fifty-two patients with UC (33 males and 19 females; mean age, $48.7 \pm 4.6$ years) received treatment at The First Affiliated Hospital of Jinzhou Medical University (Jinzhou, China) between August 2018 and June 2019, and were included in the experimental group. Among the 52 patients with UC, 23 were active cases and 29 were in remission. The patients were grouped according to the severity of the disease as follows: Mild ( $n=16)$; moderate $(n=18)$; and severe $(n=18)$. During the same period, 21 healthy subjects who underwent a physical examination at The First Affiliated Hospital of Jinzhou Medical University were included as the control group (14 males and 7 females; mean age, $42.6 \pm 5.4$ years). None of the patients had other intestinal infections, tumors, rheumatism or other autoimmune diseases. Fasting peripheral blood $(10 \mathrm{ml})$ was collected from all subjects and centrifuged at $4,000 \mathrm{x}$ g at $4^{\circ} \mathrm{C}$ for $10 \mathrm{~min}$ to separate plasma. All procedures performed in the current study were approved by the Ethics Committee of Jinzhou Medical University and written informed consent was obtained from all patients or their families.

Cell culture. Normal human colon mucosal epithelial NCM460 cells (American Type Culture Collection) were cultured in DMEM supplemented with $10 \%$ fetal bovine serum (HyClone; Cytiva), $100 \mathrm{IU} / \mathrm{ml}$ penicillin and $100 \mathrm{IU} / \mathrm{ml}$ streptomycin at $37^{\circ} \mathrm{C}, 5 \% \mathrm{CO}_{2}$ and $70 \%$ humidity. The cells were passaged every three days and those in logarithmic growth phase were collected for experiments.

Co-culture of intestinal epithelial cells. NCM460 cells $\left(1 \times 10^{5}\right)$ were seeded in 24-well plates, cultured at $37^{\circ} \mathrm{C}$ and $5 \% \mathrm{CO}_{2}$, and divided into the following groups: Negative control (NC) group; IL-6 group; plasma group; plasma + IL-6 antibody group; and IL-6 + stattic group. The cells in the NC group were not treated. The IL- 6 group was incubated with IL- 6 recombinant protein (cat. no. abs04044; Absin Bioscience Inc.) at $37^{\circ} \mathrm{C}$ for $24 \mathrm{~h}$. The plasma group was incubated with $250 \mu \mathrm{l}$ plasma from patients with UC for $24 \mathrm{~h}$. The plasma + IL-6 antibody group was incubated with $250 \mu$ l plasma from patients with UC and IL-6 antibody (cat. no. abs101505; Absin Bioscience Inc.) at $37^{\circ} \mathrm{C}$ for $24 \mathrm{~h}$. The IL-6 + stattic group was incubated at $37^{\circ} \mathrm{C}$ for $24 \mathrm{~h}$ with IL-6 recombinant protein and STAT3 signaling pathway inhibitor, stattic (cat. no. abs812053; Absin Bioscience Inc.). The stattic was dissolved in DMSO and added to the culture medium to reach a concentration of $10 \mu \mathrm{m}$. The cells were collected for subsequent assays.
Enzyme-linked immunosorbent assay (ELISA). A Human IL-6 Quantikine ELISA kit (cat. no. D6050; R\&D Systems, Inc.) was used to determine the concentration of IL-6 and the Human Haptoglobin Quantikine ELISA kit (cat. no. DHAPG0; R\&D Systems, Inc.) was used to determine the level of zonulin. First, $50 \mu \mathrm{l}$ RD1W diluent was added to each well of a microplate. Then, $50 \mu \mathrm{l}$ standards and $50 \mu \mathrm{l}$ cell culture supernatants were added into predefined wells before shaking and incubation at room temperature for $2 \mathrm{~h}$. After washing the plate with cold PBS, $100 \mu$ l conjugate was added to each well before shaking and incubation at room temperature for $2 \mathrm{~h}$. After washing the plate again with cold PBS, $100 \mu$ l substrate was added to each well before incubation at room temperature in the dark for $30 \mathrm{~min}$. Then, $100 \mu \mathrm{l}$ stop solution was added to each well before mixing by shaking the plate. Within $30 \mathrm{~min}$, the absorbance at $570 \mathrm{~nm}$ of each well was read using a microplate reader.

Detection of intestinal epithelial cell barrier permeability. NCM640 cells were seeded into 6-well plates at a density of 1x10\% /well. Millicell ${ }^{\circledR}$ chambers (EMD Millipore) were placed into 24-well plates. At 70\% confluency, NCM640 cells were trypsinized and seeded into the apical end of the Millicell chambers at a density of $1 \times 10^{5} /$ well $(0.4 \mathrm{ml})$. At the basolateral end, $0.6 \mathrm{ml}$ DMEM was added, followed by incubation at $37^{\circ} \mathrm{C}$ and $5 \% \mathrm{CO}_{2}$ for $24 \mathrm{~h}$. After replacing the medium, the cells were incubated at $37^{\circ} \mathrm{C}$ for 10 days. On days $2,5,8$ and 10 , transepithelial electrical resistance (TEER) was determined to evaluate paracellular permeability. A Millicell-Electrical Resistance System transmembrane resistance meter was used to analyze cell transmembrane resistance, which was calculated as follows: Transmembrane resistance of intestinal epithelial cells $=($ value of sample well-value of blank well $) \times$ Millicell membrane area $\left(\Omega \cdot \mathrm{cm}^{2}\right)$. The analysis was performed at $37^{\circ} \mathrm{C}$ in triplicate, and the mean value was taken as the TEER. Approximately 14-21 days later, the cells formed a compact monolayer and the TEER increased significantly, indicating that the barrier of intestinal epithelial cells was formed and ready for subsequent experiments.

Western blotting. After $24 \mathrm{~h}$ of culture, the medium was discarded, and the cells were washed twice with cold PBS. RIPA lysis buffer and protease inhibitor PMSF (Beyotime Institute of Biotechnology) were added to the cells, which were lysed on ice for $5 \mathrm{~min}$. Following centrifugation at $4^{\circ} \mathrm{C}$ and $12,000 \mathrm{x} \mathrm{g}$ for $10 \mathrm{~min}$, the supernatant was collected and mixed with $5 \mathrm{X}$ loading buffer (Beyotime Institute of Biotechnology), followed by incubation in a boiling water bath for $10 \mathrm{~min}$. The samples $(5 \mu \mathrm{l})$ were electrophoresed with 10\% SDS-PAGE at $100 \mathrm{~V}$ and transferred to a PVDF membrane at $250 \mathrm{~mA}$ for $1 \mathrm{~h}$ on ice. After blocking with $50 \mathrm{~g} / \mathrm{l}$ skimmed milk at room temperature for $1 \mathrm{~h}$, the membranes were incubated with rabbit anti-human H3K27ac (1:1,000; cat. no. 8173; Cell Signaling Technology, Inc.), phosphorylated (p)-STAT3 (1:1,000; cat. no. 9145; Cell Signaling Technology, Inc.), STAT3 (1:1,000; cat. no. 12640; Cell Signaling Technology, Inc.) or GAPDH $(1: 4,000)$ primary antibodies (cat. no. ab9485; Abcam) at $4^{\circ} \mathrm{C}$ overnight. After washing with TBST three times for $10 \mathrm{~min}$, horseradish peroxidase-labelled goat anti-rabbit secondary antibody (1:4,000; cat. no. ab6721; Abcam) was added for incubation at room 
temperature for $1 \mathrm{~h}$. After washing with TBST three times for $10 \mathrm{~min}$, the membranes were developed with electrochemiluminescence solution (Beyotime Institute of Biotechnology). The expression of target proteins was calculated against GAPDH.

Fluorescein diffusion experiment. NCM640 cells $\left(1 \times 10^{6}\right)$ were added to a Transwell chamber and cultured overnight. After washing the cells with HBSS (pH 7.4) three times, the cells were incubated with $\mathrm{HBSS}$ at $37^{\circ} \mathrm{C}$ for $30 \mathrm{~min}$. After discarding the HBSS, fluorescein $(40 \mu \mathrm{g} / \mathrm{ml})$ was added to the top of the Transwell chamber, followed by incubation at $37^{\circ} \mathrm{C}$ for $1 \mathrm{~h}(20)$. Then, fluid from the lower chamber was collected for the determination of absorbance using a fluorescence spectrophotometer (excitation wavelength, $427 \mathrm{~nm}$; emission wavelength, $536 \mathrm{~nm}$ ). The fluorescence intensity was calculated to analyze the degree of diffusion of fluorescein (20).

Total RNA extraction. Cells $\left(1 \times 10^{6}\right)$ were lysed with $1 \mathrm{ml}$ TRIzol ${ }^{\circledR}$ (Thermo Fisher Scientific, Inc.) according to the manufacturer's instructions, before extraction of total RNA. mRNA was reverse-transcribed into cDNA using a BeyoRT ${ }^{\mathrm{TM}}$ II cDNA First Strand Synthesis Kit (Beyotime Institute of Biotechnology) and stored at $-80^{\circ} \mathrm{C}$. The reaction system was composed of $5 \mu \mathrm{l}$ RNA template, $1 \mu \mathrm{l}$ Oligo $(\mathrm{dT})_{18}$ primer, $4 \mu \mathrm{l}$ reaction buffer $(5 \mathrm{X}), 1 \mu \mathrm{l}$ RNase inhibitor $(20 \mathrm{U} / \mu \mathrm{l}), 1 \mu \mathrm{l}$ dNTP Mix (10 mM each), $1 \mu$ l BeyoRT II M-MLV reverse transcriptase and $7 \mu 1 \mathrm{H}_{2} \mathrm{O}$. After thorough mixing, reverse transcription (RT) was performed at $42^{\circ} \mathrm{C}$ for $60 \mathrm{~min}$. Then, RNAase-free $\mathrm{H}_{2} \mathrm{O}$ was added to the RT product to reach a total volume of 50 and $5 \mu \mathrm{l}$ was used for subsequent quantitative PCR (qPCR).

$q P C R$. The expression levels of claudin (CLDN) 1 and CLDN2 mRNA were determined using a BeyoFast ${ }^{\mathrm{TM}}$ Probe qPCR kit (Beyotime Institute of Biotechnology) with GAPDH serving as an internal reference. The reaction system $(30 \mu 1)$ was composed of $5 \mu \mathrm{l}$ cDNA, $10 \mu \mathrm{l}$ BeyoFast Probe qPCR Mix, $1 \mu \mathrm{l}$

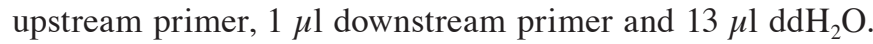
The reaction conditions were as follows: Initial denaturation at $95^{\circ} \mathrm{C}$ for $5 \mathrm{~min}$; denaturation at $95^{\circ} \mathrm{C}$ for $30 \mathrm{sec}$, annealing at $60^{\circ} \mathrm{C}$ for $30 \mathrm{sec}$ and elongation at $72^{\circ} \mathrm{C}$ for $1 \mathrm{~min}(40$ cycles); final elongation at $72^{\circ} \mathrm{C}$ for $5 \mathrm{~min}$. The primer sequences were as follows: CLDN1 forward, 5'-TTGGGCTTCATTCTCGCC TT-3' and reverse, 5'-CTGGCATTGACTGGGGTCAT-3'; CLDN2 forward, 5'-CCTTGTACTTCGCTCCCCTC-3' and reverse, 5'-ACAATGCTGGCACCGACATA-3'; GAPDH forward, 5'-CGGAGTCAACGGATTTGGTCGTAT-3' and reverse, 5'-AGCCTTCTCCATGGTGGTGAAGAC-3'. The $2^{-\triangle \Delta \mathrm{Cq}}$ method (21) was used to determine the relative expression of CLDN1 and CLDN2 mRNA against GAPDH. Each sample was evaluated in triplicate.

Chromatin immunoprecipitation (ChIP)-qPCR . Co-immunoprecipitation was performed using a SimpleChIP ${ }^{\circledR}$ Enzymatic Chromatin IP Kit (Magnetic Beads; Cell Signaling Technology, Inc.) according to the manufacturer's instructions. Two pairs of primers were designed for different promoters of CLDN1 and CLDN2 genes. The first pair of primers for CLDN1 were: Forward, 5'-TGCAGAGACAAGTGATGGAACGAC-3' and reverse, 5'-AAGAGCTGCAGTTTTAGGTTTAATA-3'. The second pair of primers for CLDN1 were: Forward, 5'-TAT TAAACCTAAAACTGCAGCTCTT-3' and reverse, 5'-GCT CCTGTAAGGCGTTTCACG-3'. The first pair of primers for CLDN2 were: Forward, 5'-GGCTAGGCCACTACTCTCTAG GC-3' and reverse, 5'-GCCTGCTGTTTAATACATTGCCA-3'. The second pair of primers for CLDN2 were: Forward, 5'-TCC TGGCTTTGTCCAGCTGCCA-3' and reverse, 5'-TGGCAG CTGGACAAAGCCAGGA-3'. The $2^{-\Delta \Delta \mathrm{Cq}}$ method (21) was used to quantify $\mathrm{H} 3 \mathrm{~K} 27 \mathrm{ac}$ enrichment. qPCR was performed as aforementioned.

Statistical analysis. The results were analyzed using SPSS 18.0 statistical software (SPSS, Inc.) and data are expressed as means \pm standard deviations. All data underwent a normality test. If the data demonstrated normal distribution and the variance was homogeneous, differences between multiple groups were analyzed using one-way ANOVA and Dunnett's test, while comparisons between two groups were performed using paired or unpaired Student's t-test. If the data were not normally distributed or the variance was not uniform, differences between multiple groups were analyzed using Kruskal-Wallis test and Tamhane's T2 or Dunnett's T3 method, while comparisons between two groups were conducted using the Mann-Whitney $\mathrm{U}$ test. $\mathrm{P}<0.05$ was considered to indicate a statistically significant difference.

\section{Results}

IL-6 content is elevated in plasma from patients with UC and increases with progression of the disease. ELISA was used to evaluate the content of IL-6 in peripheral blood. The data (Fig. 1A) indicated that IL-6 content in plasma from patients with UC $(80.5 \pm 4.6 \mathrm{pg} / \mathrm{ml})$ was significantly higher than that of the healthy subjects $(22.6 \pm 2.7 \mathrm{pg} / \mathrm{ml})(\mathrm{P}<0.05)$. Furthermore, IL- 6 content in plasma from patients with active UC $(110.5 \pm 5.1 \mathrm{pg} / \mathrm{ml})$ was significantly higher than that in patients who were in remission $(68.4 \pm 3.4 \mathrm{pg} / \mathrm{ml})(\mathrm{P}<0.05)$ as presented in Fig. 1B. Regarding disease severity, the IL-6 content in plasma from patients with UC in the moderate group $(100.6 \pm 4.3 \mathrm{pg} / \mathrm{ml})$ and severe group $(118.7 \pm 6.4 \mathrm{pg} / \mathrm{ml})$ was significantly higher than that in the mild group $(58.4 \pm 2.6 \mathrm{pg} / \mathrm{ml})$ $(\mathrm{P}<0.05)$ as presented in Fig. 1C. The results indicate that IL-6 levels are elevated in the plasma of patients with UC and that it is increases with the progression of the disease.

IL-6 induces intestinal epithelial cell barrier injury. To evaluate intestinal epithelial cell barrier permeability, the TEER was determined and Millicell inserts were used. The data demonstrated that the TEER value of monolayer cells in the NC group was $250 \Omega \cdot \mathrm{cm}^{2}$. After a 12-h treatment with IL-6, plasma from patients with UC or UC plasma containing IL- 6 antibody, the TEER values of the IL- 6 group and the plasma group were significantly lower than those of the NC group $(\mathrm{P}<0.05)$. In addition, the TEER value of the plasma + IL-6 antibody group was significantly higher than that of the plasma group ( $\mathrm{P}<0.05$; Fig. 2A). The Millicell data showed that the permeability for fluorescein yellow in the IL-6 group (26.5 $\pm 0.65 \%)$ and plasma group $(38.5 \pm 0.89 \%)$ was significantly higher than that in the NC group $(2.53 \pm 0.14 \%)$ 

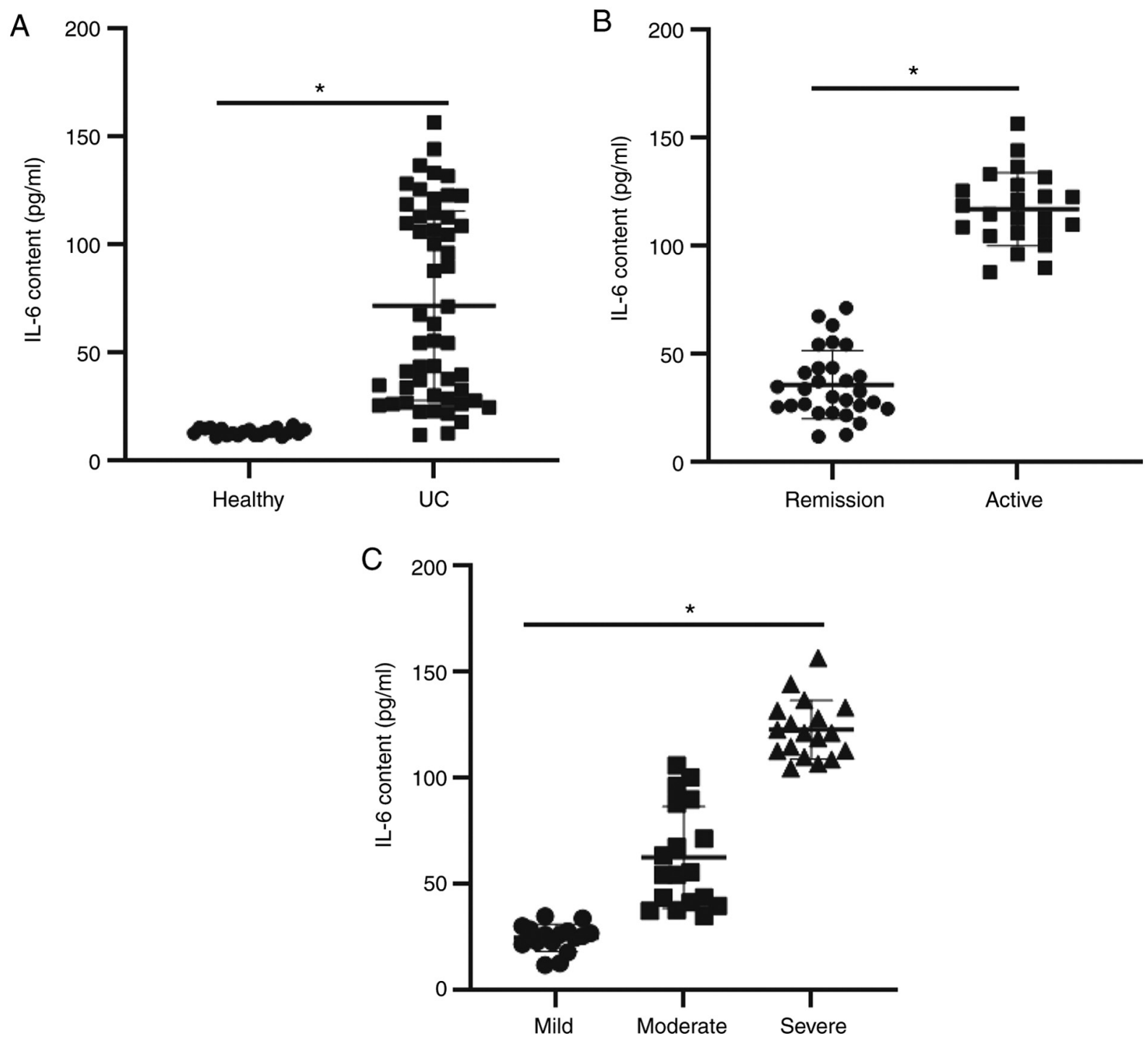

Figure 1. ELISA was used to determine the plasma level of IL-6 in (A) healthy subjects or patients with UC, (B) patients in remission from UC or with active $\mathrm{UC}$, and (C) patients with mild, moderate or severe cases of UC. ${ }^{*} \mathrm{P}<0.05$. UC, ulcerative colitis.

$(\mathrm{P}<0.05)$. Furthermore, the permeability for fluorescein yellow in the plasma + IL-6 antibody group (22.7 $\pm 0.71 \%)$ was significantly lower than that in the plasma group $(\mathrm{P}<0.05$; Fig. $2 \mathrm{~B})$. The result indicates that IL-6 induces intestinal epithelial cell barrier injury.

IL-6 regulates barrier function by influencing the expression of tight junction-related proteins in the epithelium. Comparable to epithelial-mesenchymal transition markers, E-cadherin and N-cadherin, CLDN1, CLDN2 and zonulin are markers of epithelial tight junctions. In the present study, these molecular markers were detected to evaluate intestinal epithelial cell barrier permeability. To analyze the effect of IL-6 on the release and expression of these monolayer epithelial cell barrier-associated proteins, ELISA and RT-qPCR were conducted. After stimulating NCM640 cells with IL-6 for 6 h, the zonulin content in the culture supernatant of the cells was observed to be significantly higher than that of the NC group $(\mathrm{P}<0.05)$. Similarly, treatment with UC plasma also elevated the level of zonulin when compared to the NC group $(\mathrm{P}<0.05)$. However, addition of the IL- 6 antibody reduced the content of zonulin when compared with that of the plasma group $(\mathrm{P}<0.05$; Fig. 3A). RT-qPCR demonstrated that the mRNA expression levels of CLDN1 and CLDN2 in the IL-6 or plasma group were significantly lower than that of the NC group $(\mathrm{P}<0.05)$. However, the addition of IL-6 antibody significantly increased the expression levels of CLDN1 and CLDN2 mRNA when compared with the plasma group $(\mathrm{P}<0.05$; Fig. $3 \mathrm{~B}$ and $\mathrm{C})$. The results suggest that IL- 6 regulates barrier function by influencing the expression of tight junction-related proteins in the epithelium.

IL-6 regulates the barrier function of intestinal epithelial cells via STAT3. To evaluate the effect of STAT3 on the barrier function of intestinal epithelial cells, NCM640 cells were treated with stattic to inhibit the STAT3 signaling pathway. Western blotting indicated that the level of p-STAT3 in the IL-6 group was significantly higher than that in the $\mathrm{NC}$ group $(\mathrm{P}<0.05)$ and the level of p-STAT3 in the IL-6 + stattic group was significantly lower than in the IL-6 group ( $\mathrm{P}<0.05$; Fig. 4A). The TEER value in the IL-6 group was significantly lower than that in the NC group $(\mathrm{P}<0.05)$, while that in the IL- $6+$ stattic group 

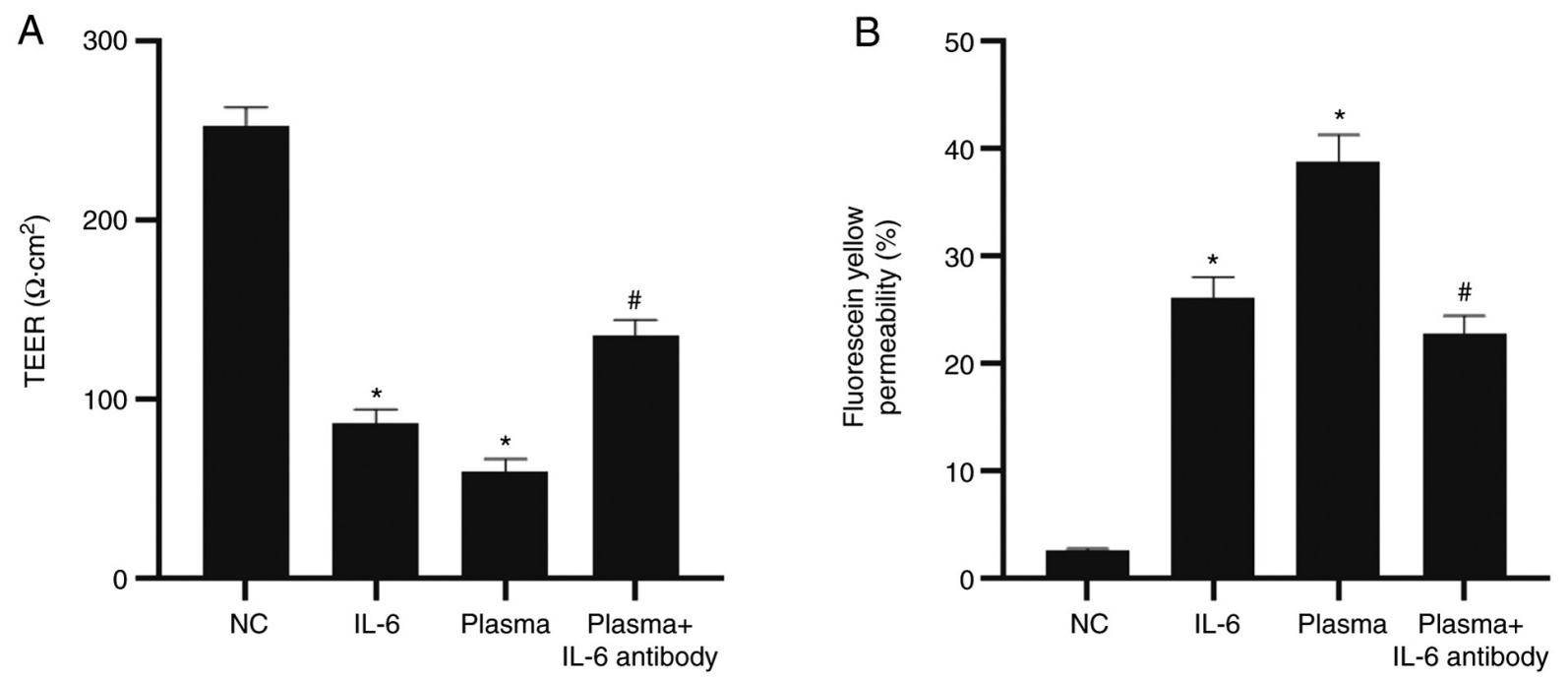

Figure 2. Effects of IL-6 and plasma from patients with UC on intestinal epithelial cell barrier injury. (A) TEER values and (B) permeability for fluorescein yellow of NCM640 cells treated with IL-6, plasma from patients with UC or UC plasma containing IL-6 antibody. "P<0.05 vs. NC group; ${ }^{\text {*P }}<0.05$ vs. plasma group. UC, ulcerative colitis; TEER, transepithelial electrical resistance; NC, negative control.
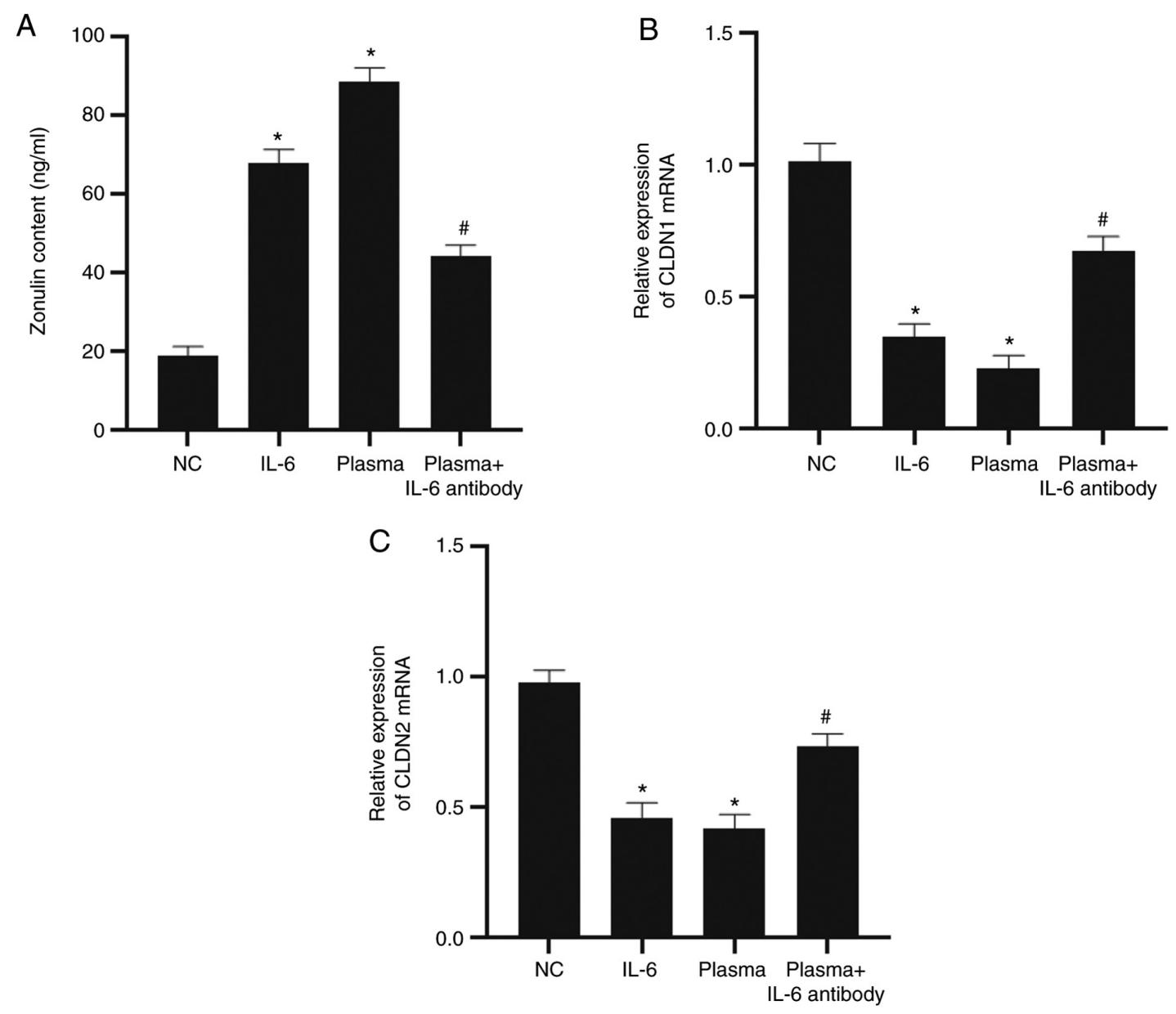

Figure 3. Expression of tight junction-related proteins. (A) Zonulin content, and (B) CLDN1 and (C) CLDN2 mRNA expression levels in NCM640 cells treated with IL-6, plasma from patients with UC or UC plasma containing IL- 6 antibody. " $\mathrm{P}<0.05$ vs. NC group; ${ }^{*} \mathrm{P}<0.05$ vs. plasma group. CLDN, claudin; UC, ulcerative colitis; NC, negative control.

was significantly higher than that in the IL-6 group $(\mathrm{P}<0.05$; Fig. 4B). In addition, fluorescein yellow permeability in the IL-6 group was significantly higher than that in the NC group
$(\mathrm{P}<0.05)$, while that in the IL- $6+$ stattic group was significantly lower than that in the IL-6 group $(\mathrm{P}<0.05$; Fig. $4 \mathrm{C})$. ELISA showed that zonulin content in the culture supernatant of 
A
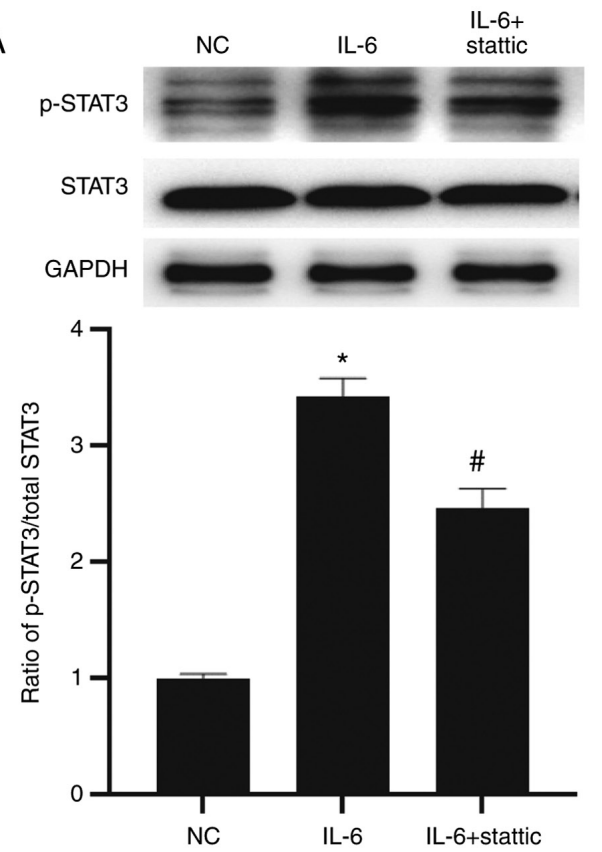

C

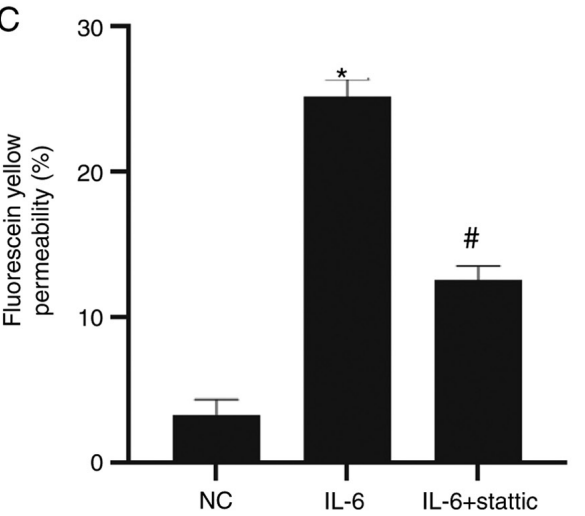

$\mathrm{E}$

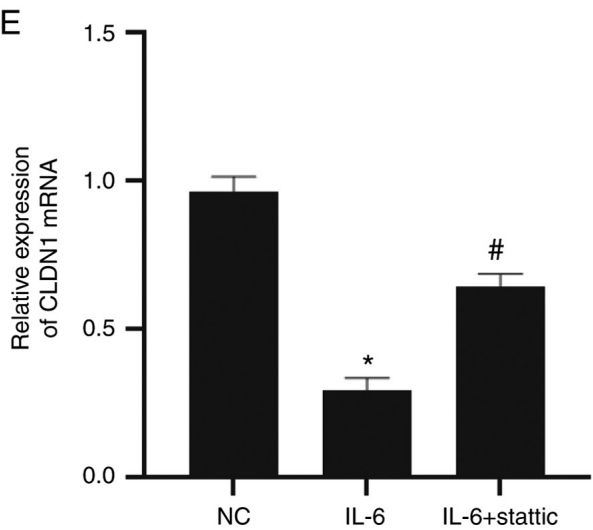

B
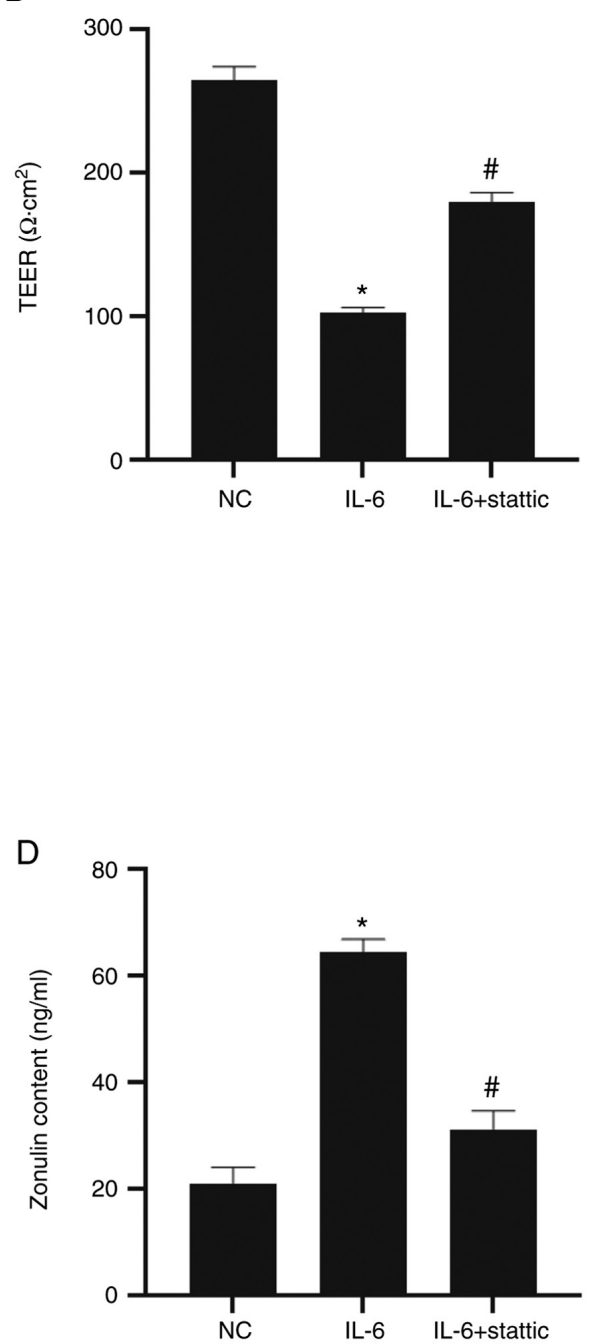

$\mathrm{F}$

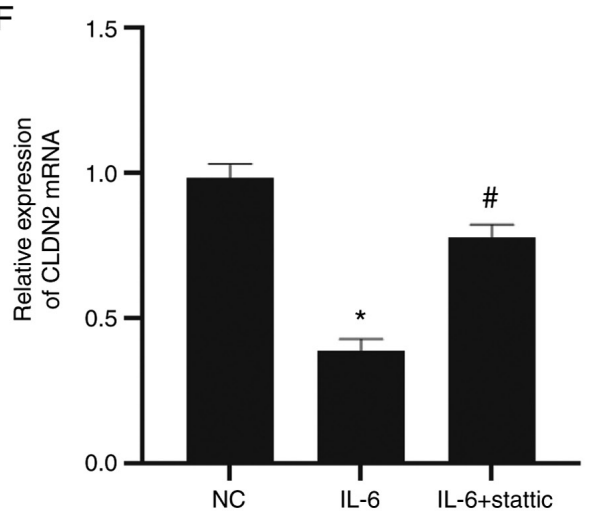

Figure 4. IL-6 regulates the barrier function of intestinal epithelial cells via the STAT3 signaling pathway. (A) Ratio of p-STAT3/total STAT3 in NCM640 cells as determined by western blotting. (B) TEER values and (C) fluorescein yellow permeability of NCM640 cells. (D) Zonulin content, and (E) CLDN1 and (F) CLDN2 mRNA expression levels in NCM640 cells. NCM640 cells in the NC group were not treated; those in the IL-6 group were treated with IL-6 recombinant protein; those in the IL- 6 + stattic group were treated with IL- 6 and STAT3 signaling pathway inhibitor, stattic. ${ }^{*} \mathrm{P}<0.05$ vs. NC group; ${ }^{*} \mathrm{P}<0.05$ vs. IL-6 group. p, phosphorylated; TEER, transepithelial electrical resistance; CLDN, claudin; NC, negative control.

NCM640 cells of the IL-6 group was significantly higher than that in the $\mathrm{NC}$ group $(\mathrm{P}<0.05)$, while that in the IL-6 + stattic group was significantly lower than that in the IL-6 group ( $\mathrm{P}<0.05$; Fig. 4D). RT-qPCR showed that CLDN1 and CLDN2 mRNA expression levels in the IL-6 group were significantly lower than those in the $\mathrm{NC}$ group $(\mathrm{P}<0.05)$, and that CLDN1 and CLDN2 mRNA expression levels in the IL-6 + stattic group were significantly higher than in the IL-6 group $(\mathrm{P}<0.05$; Fig. 4E and F). The results indicate that IL-6 regulates the barrier function of intestinal epithelial cells via STAT3.

IL-6/STAT3 signaling pathway regulates the transcription of CLDN1 and CLDN2 by affecting the enrichment of histone H3K27ac in their promoter regions. To evaluate the effect 


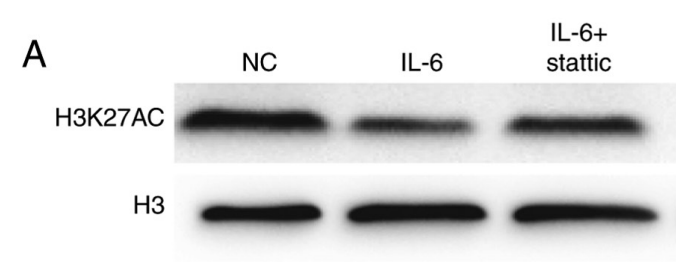

B

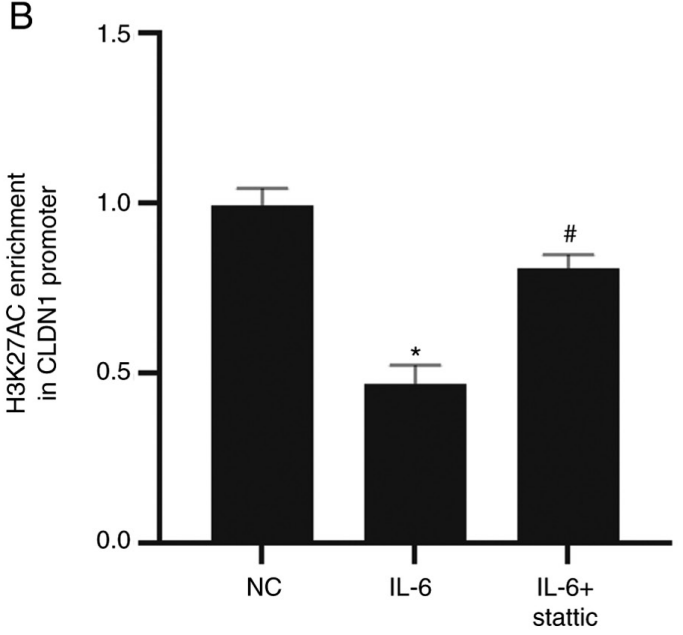

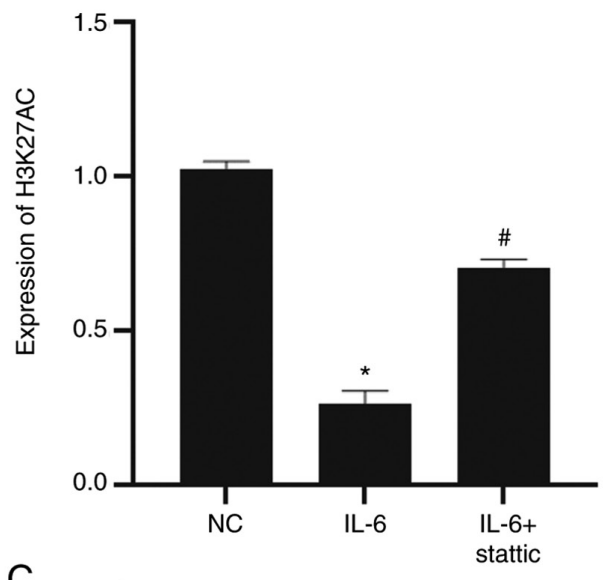

C

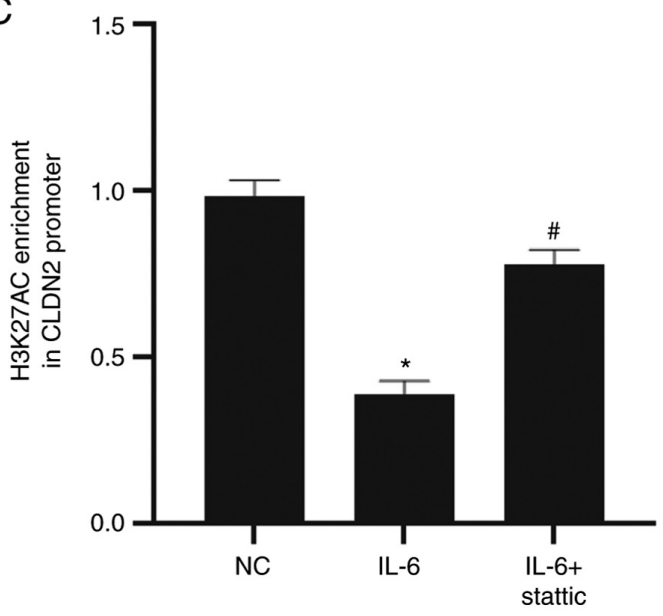

Figure 5. IL-6/STAT3 signaling pathway affects the transcription of CLDN1 and CLDN2 via H3K27ac. (A) Expression of H3K27ac in NCM640 cells as determined by western blotting. (B and C) Enrichment of H3K27ac in the promoter regions of (B) CLDN1 and (C) CLDN2 as determined by chromatin immunoprecipitation-quantitative PCR. " $\mathrm{P}<0.05$ vs. NC group; ${ }^{\mathrm{P}}<0.05$ vs. IL-6 group. CLDN, claudin; NC, negative control.

of the IL-6/STAT3 signaling pathway on the H3K27ac level in NCM640 cells and H3K27ac enrichment on the promoter regions of CLDN1 and CLDN2, western blotting and ChIP-qPCR were conducted. The data showed that the $\mathrm{H} 3 \mathrm{~K} 27 \mathrm{ac}$ level in cells of the IL-6 group was significantly lower than that in the $\mathrm{NC}$ group $(\mathrm{P}<0.05)$ and that the $\mathrm{H} 3 \mathrm{~K} 27 \mathrm{ac}$ level in the IL-6 + stattic group was significantly higher than that in the IL-6 group ( $\mathrm{P}<0.05$; Fig. 5A). The enrichment of $\mathrm{H} 3 \mathrm{~K} 27 \mathrm{ac}$ in the promoter regions of CLDN1 and CLDN2 in the IL-6 group was significantly lower than in the NC group $(\mathrm{P}<0.05$ for both), while that of the IL- $6+$ stattic group was significantly higher than the IL-6 group $(\mathrm{P}<0.05$ for both; Fig. 5B and C). The results suggest that the IL-6/STAT3 signaling pathway regulates the transcription of CLDN1 and CLDN2 by affecting the enrichment of histone H3K27ac in their promoter regions.

\section{Discussion}

Injury of the intestinal epithelial barrier is the predominant pathological change in UC and its main characteristics include intestinal epithelial cell apoptosis, normal intestinal epithelial cell barrier damage, infiltration of subcutaneous lymphocytes of the intestine and cytokine expression, leading to damage of the intestinal epithelium $(22,23)$. As many cytokines are found in the peripheral blood and intestinal tissue of patients with
$\mathrm{UC}$, the roles of these cytokines in intestinal epithelial damage have become a notable research topic.

IL-6 plays important regulatory roles in cardiovascular diseases, lipid metabolism, mitochondrial activity, and the occurrence and development of tumors $(24,25)$. IL- 6 can be synthesized and secreted by almost all stromal cells and immune cells, such as T cells, macrophages and epithelial tumor cells $(26,27)$. IL-6 also plays important roles at different stages of inflammation. For example, significant quantities of IL- 6 are secreted by monocytes and macrophages at the early stage of infectious inflammation and participates in host immune defense (28). Furthermore, IL-6 participates in humoral immune regulation by regulating $\mathrm{B}$ cell functions (29). The expression of IL-6 in the peripheral blood of patients with UC is significantly upregulated and the concentration of IL-6 is negatively correlated with the response of patients to infliximab (30). In the present study, the level of IL-6 in the peripheral blood of patients with UC was observed to be significantly elevated and was higher in patients with active UC when compared with those who were in remission. In addition, the expression level of IL-6 in patients with moderate or severe UC was higher than that in patients with mild UC. These results indicate that the IL-6 expression level was positively associated with the progression of UC.

Intestinal barrier damage is the main pathological change in UC (31). The intestinal barrier includes normal flora, a 
mucus layer, intestinal epithelial cell layer and intestinal immune system, among which the intestinal epithelial cells are particularly important in the composition and maintenance of the intestinal barrier (32). The degree of intestinal barrier damage can be reflected by the TEER value, the diffusion efficiency of fluorescein yellow and the release of zonulin (33). TEER is a simple and authoritative method of evaluating the permeability of monolayer epithelial cells (34). In the present study, it was found that IL- 6 and plasma from patients with UC significantly decreased the TEER value and promoted the diffusion of fluorescein yellow and the release of zonulin, whilst reducing the expression of tight junction proteins CLDN1 and CLDN2 at the molecular level. After adding the IL-6 antibody, the TEER value, fluorescein yellow diffusion, zonulin release and the expression levels of CLDN1 and CLDN2 in the plasma group were significantly reversed. These results indicated that IL- 6 promoted intestinal epithelial cell damage in patients with UC. As a downstream transducer of IL-6, STAT3 exerts important biological functions in many types of disease, such as tumors, autoimmune diseases and pulmonary fibrosis $(35,36)$. In the present study, the addition of STAT3 inhibitor recovered the damage of intestinal epithelial cells induced by IL-6, suggesting that IL-6 exerted its biological functions via STAT3.

The IL-6/STAT3 signaling pathway is important in intestinal inflammation and colon cancer. For example, inhibition of the IL-6/STAT3 signaling pathway improves intestinal injury in acute enteritis (37). In addition, the IL-6/STAT3/suppressor of cytokine signaling-3 (SOCS3) signaling pathway plays an important role in the carcinogenesis of enteritis (38). Another study demonstrated that the expression imbalance of the IL-6/STAT3/SOCS3 signaling pathway exists in the occurrence of tumors associated with UC or enteritis (39). The conclusions of the aforementioned studies concur with the results of the present study. Notably, the present study also found that the permeability of cells in the IL-6 rescue group was only partially restored. This indicates the existence of an underlying mechanism independent of IL-6, which regulates intestinal epithelial barrier permeability. For example, recombinant IL-17A-dependent regulation of the tight junction protein occludin during epithelial injury impacts permeability and maintains barrier integrity (40). Future studies are required to investigate potential factors in the regulation of epithelial barrier permeability.

$\mathrm{H} 3 \mathrm{~K} 27 \mathrm{ac}$ is an important histone modification. When $\mathrm{H} 3 \mathrm{~K} 27 \mathrm{ac}$ is enriched in promoter regions, it promotes the opening of chromatin, so that transcriptional factors can combine with promoter region sequences to initiate downstream gene transcription (41). In the present study, the data showed that CLDN1 and CLDN2 were negatively regulated by the IL-6/STAT3 signaling pathway. As STAT3 is a transcription factor responsible for initiating gene transcription, the present study speculated that there were other factors that affected the expression of CLDN1 and CLDN2. It was discovered that the IL-6/STAT3 signaling pathway directly inhibited the expression of H3K27ac in intestinal epithelial cells. Using ChIP-qPCR, the present study demonstrated that IL-6 reduced the enrichment of $\mathrm{H} 3 \mathrm{~K} 27 \mathrm{ac}$ in the promoter regions of CLDN1 and CLDN2. This indicated that the IL-6/STAT3 signaling pathway affected the barrier function of intestinal epithelial cells by downregulating the expression level of H3K27ac.
Thus, the present study demonstrates that the expression level of IL-6 in the peripheral blood of patients with UC is increased significantly and is positively associated with the development of UC. Furthermore, the IL-6/STAT3 signaling pathway affects the function of the intestinal barrier by affecting the H3K27ac level in intestinal epithelial cells. However, there were certain limitations of the present study; only a single cell line, NCM460 was used. Although the NCM460 cell line is one of the most commonly used normal intestinal epithelial cell lines, the influence of the IL-6/STAT3 signaling pathway on NCM460 cells does not represent its impact on intestinal epithelial cells as a whole. Therefore, the scope of our work will be expanded further to verify this result on other cell lines in future studies.

\section{Acknowledgements}

Not applicable.

\section{Funding}

No funding was received.

\section{Availability of data and materials}

The datasets used and/or analyzed during the current study are available from the corresponding author on reasonable request.

\section{Authors' contributions}

YL and YJ contributed to the design of the study. YL, YJ and TC performed the experiments. YL, YJ and JZ analyzed the data. YL interpreted results and prepared the manuscript. YL and YJ confirm the authenticity of all the raw data. All authors read and approved the final version of the manuscript.

\section{Ethics approval and consent to participate}

All procedures performed in the current study were approved by the Ethics Committee of Jinzhou Medical University. Written informed consent was obtained from all patients or their families.

\section{Patient consent for publication}

Written informed consents for publication of any associated data and accompanying images were obtained from all patients or their parents, guardians or next of kin.

\section{Competing interests}

The authors declare that they have no competing interests.

\section{References}

1. Sahu P, Bopanna S, Kedia S and Ahuja V: Risk of colorectal cancer in Asian patients with ulcerative colitis. J Gastroenterol Hepatol 35: 1451, 2020.

2. Wakai M, Hayashi R, Tanaka S, Naito T, Kumada J, Nomura M, Takigawa H, Oka S, Ueno Y, Ito M and Chayama K: Serum amyloid $\mathrm{A}$ is a better predictive biomarker of mucosal healing than C-reactive protein in ulcerative colitis in clinical remission. BMC Gastroenterol 20: 85, 2020. 
3. Akiyama S, Traboulsi C, Rai V and Rubin DT: Re: ${ }^{18}$ F-FDG PET-MR enterography in predicting histological active disease using the Nancy index in ulcerative colitis: A randomized controlled trial. Eur J Nucl Med Mol Imaging 47: 2247, 2020.

4. Biemans VBC, Sleutjes JAM, de Vries AC, Bodelier AGL, Dijkstra G, Oldenburg B, Löwenberg M, van Bodegraven AA, van der Meulen-de Jong AE, de Boer NKH, et al: Tofacitinib for ulcerative colitis: Results of the prospective dutch initiative on crohn and colitis (ICC) registry. Aliment Pharmacol Ther 51: 880-888, 2020.

5. Longhi MS and Kokkotou E: Lnc-ing RNA expression with disease pathogenesis: MALAT1 and ANRIL in Ulcerative Colitis. Dig Dis Sci 65: 3061-3063, 2020.

6. Rozich JJ, Holmer A and Singh S: Effect of lifestyle factors on outcomes in patients with inflammatory bowel diseases. Am J Gastroenterol 115: 832-840, 2020

7. Itsuji T, Tonomura H,Ishibashi H, Mikami Y, Nagae M, Takatori R, Tanida T, Matsuda KI, Tanaka M and Kubo T: Hepatocyte growth factor regulates HIF-1 $\alpha$-induced nucleus pulposus cell proliferation through MAPK-, PI3K/Akt-, and STAT3-mediated signaling. J Orthop Res 2020 (Epub ahead of print)

8. Zhao C, Yang L, Zhou F, Yu Y, Du X, Xiang Y, Li C, Huang X, Xie C, Liu Z, et al: Feedback activation of EGFR is the main cause for STAT3 inhibition-irresponsiveness in pancreatic cancer cells. Oncogene 39: 3997-4013, 2020.

9. Samiea A, Yoon JSJ, Cheung ST, Chamberlain TC and Mui AL: Interleukin-10 contributes to PGE2 signalling through upregulation of EP4 via SHIP1 and STAT3. PLoS One 15: e0230427, 2020

10. Shi S, Song L, Liu Y and He Y: Activation of CREB protein with tabersonine attenuates STAT3 during atherosclerosis in apolipoprotein E-Deficient mice. Dose Response 18: 1559325820912067, 2020.

11. Kim SH, Hong JH, Yang WK, Geum JH, Kim HR, Choi SY, Kang YM, An HJ and Lee YC: Herbal combinational medication of glycyrrhiza glabra, agastache rugosa containing glycyrrhizic acid, tilianin inhibits neutrophilic lung inflammation by affecting CXCL2, Interleukin-17/STAT3 signal pathways in a murine model of COPD. Nutrients 12: 926, 2020.

12. Zhao T, Jin F, Xiao D, Wang H, Huang C, Wang X, Gao S, Liu J, Yang S and Hao J: IL-37/STAT3/HIF-1 $\alpha$ negative feedback signaling drives gemcitabine resistance in pancreatic cancer. Theranostics 10: 4088-4100, 2020.

13. Jiang CQ, Ma LL, Lv ZD, Feng F, Chen Z and Liu ZD: Polydatin induces apoptosis and autophagy via STAT3 signaling in human osteosarcoma MG-63 cells. J Nat Med 74: 533-544, 2020

14. Yu CI, Cheng CI, Kang YF, Chang PC, Lin IP, Kuo YH, Jhou AJ, Lin MY, Chen CY and Lee CH: Hispidulin inhibits neuroinflammation in lipopolysaccharide-activated BV2 microglia and attenuates the activation of Akt, NF- $\kappa \mathrm{B}$, and STAT3 pathway. Neurotox Res 38: 163-174, 2020.

15. Chandra V, Bhattacharyya S, Schmiedel BJ, Madrigal A, Gonzalez-Colin C, Fotsing S, Crinklaw A, Seumois G, Mohammadi P, Kronenberg M, et al: Promoter-interacting expression quantitative trait loci are enriched for functional genetic variants. Nat Genet 53: 110-119, 2021

16. Song M, Yang Q, Zhang F, Chen L, Su H, Yang X, He H, Liu F, Zheng J, Ling M, et al: Hyodeoxycholic acid (HDCA) suppresses intestinal epithelial cell proliferation through FXR-PI3K/AKT pathway, accompanied by alteration of bile acids metabolism profiles induced by gut bacteria. FASEB J 34: 7103-7117, 2020.

17. Du G, Xiong L, Li X, Zhuo Z, Zhuang X, Yu Z, Wu L, Xiao D, Liu Z, Jie M, et al: Peroxisome elevation induces stem cell differentiation and intestinal epithelial repair. Dev Cell 53: 169-184.e11, 2020.

18. Pearce SC, Weber GJ, van Sambeek DM, Soares JW, Racicot K and Breault DT: Intestinal enteroids recapitulate the effects of short-chain fatty acids on the intestinal epithelium. PLoS One 15 e0230231, 2020.

19. Tkáčiková L', Mochnáčová E, Tyagi $\mathrm{P}, \mathrm{Kiššová} \mathrm{Z} \mathrm{and} \mathrm{Bhide} \mathrm{M}$ : Comprehensive mapping of the cell response to $\mathrm{E}$. coli infection in porcine intestinal epithelial cells pretreated with exopolysaccharide derived from Lactobacillus reuteri. Vet Res 51: 49, 2020

20. Lin CW, Wang Y, Challa P, Epstein DL and Yuan F. Transscleral diffusion of ethacrynic acid and sodium fluorescein. Mol Vis 13: 243-251, 2007.

21. Livak KJ and Schmittgen TD: Analysis of relative gene expression data using real-time quantitative PCR and the 2(-Delta Delta C(T)) method. Methods 25: 402-408, 2001.

22. Wei F, Lang Y, Shen Q, Xu L, Cheng N, Chu Y, Lyu H and Chen F: Osteopontin-loaded PLGA nanoparticles enhance the intestinal mucosal barrier and alleviate inflammation via the NF- $\mathrm{KB}$ signaling pathway. Colloids Surf B Biointerfaces 190: 110952, 2020.
23. Wang $\mathrm{S}$, Wu J, Wang F, Wang $\mathrm{H}, \mathrm{Wu} \mathrm{Z}$, Wu $\mathrm{S}$ and Bao W: Expression pattern analysis of antiviral genes and inflammatory cytokines in PEDV-Infected porcine intestinal epithelial cells. Front Vet Sci 7: 75, 2020

24. St Paul M, Saibil SD, Lien SC, Han S, Sayad A, Mulder DT, Garcia-Batres CR, Elford AR, Israni-Winger K, Robert-Tissot C, et al: IL6 Induces an IL22 ${ }^{+} \mathrm{CD} 8^{+} \mathrm{T}-$ cell subset with potent antitumor function. Cancer Immunol Res 8: 321-333, 2020.

25. Kim JH, Kim WS and Park C: Interleukin-6 mediates resistance to PI3K-pathway-targeted therapy in lymphoma. BMC Cancer 19: 936, 2019.

26. Nilsson AM, Tufvesson E, Hesselstrand R, Olsson P, Wollmer P and Mandl T: Increased B-cell activating factor, interleukin-6, and interleukin-8 in induced sputum from primary Sjögren's syndrome patients. Scand J Rheumatol 48: 149-156, 2019.

27. Zhou J, Jiang Y, Zhao J, Zhang H, Fu J, Luo P, Ma Y, Zou D, Gao H, $\mathrm{Hu} \mathrm{J}$, et al: Dp44mT, an iron chelator, suppresses growth and induces apoptosis via RORA-mediated NDRG2-IL6/JAK2/STAT3 signaling in glioma. Cell Oncol (Dordr) 43: 461-475, 2020.

28. Sureda A, Martorell M, Bibiloni MDM, Bouzas C, Gallardo-Alfaro L, Mateos D, Capó X, Tur JA and Pons A: Effect of free fatty acids on inflammatory gene expression and hydrogen peroxide production by ex vivo blood mononuclear cells. Nutrients 12: 146, 2020.

29. Rezaee D, Bandehpour M, Kazemi B and Salehi M: Role of intrauterine administration of transfected peripheral blood mononuclear cells by GM-CSF on embryo implantation and pregnancy rate in mice. Mol Hum Reprod 26: 101-110, 2020.

30. Nishida Y, Hosomi S, Watanabe K, Watanabe K, Yukawa T, Otani K, Nagami Y, Tanaka F, Taira K, Kamata N, et al: Serum interleukin-6 level is associated with response to infliximab in ulcerative colitis. Scand J Gastroenterol 53: 579-585, 2018.

31. Ding S, Song Y, Brulois KF, Pan J, Co JY, Ren L, Feng N, Yasukawa LL, Sánchez-Tacuba L, Wosen JE, et al: Retinoic acid and lymphotoxin signaling promote differentiation of human intestinal M cells. Gastroenterology 159: 214-226.e1, 2020.

32. Zhang JC, Chen P, Zhang C, Khalil MM, Zhang NY, Qi DS, Wang YW and Sun LH: Yeast culture promotes the production of aged laying hens by improving intestinal digestive enzyme activities and the intestinal health status. Poult Sci 99: 2026-2032, 2020.

33. Domenech J, Hernández A, Demir E, Marcos R and Cortés C: Interactions of graphene oxide and graphene nanoplatelets with the in vitro Caco-2/HT29 model of intestinal barrier. Sci Rep 10: $2793,2020$.

34. Xia ZY, Luo C, Liu BW, Bian XQ, Li Y, Pang AM, Xu YH, Tan HM and Zhao YH: Shengui Sansheng Pulvis maintains blood-brain barrier integrity by vasoactive intestinal peptide after ischemic stroke. Phytomedicine 67: 153158, 2020.

35. Wu J, Gao FX, Wang C, Qin M, Han F, Xu T, Hu Z, Long Y, He XM, Deng X, et al: IL-6 and IL-8 secreted by tumour cells impair the function of NK cells via the STAT3 pathway in oesophageal squamous cell carcinoma. J Exp Clin Cancer Res 38: 321, 2019.

36. Babiuch K, Kuśnierz-Cabala B, Kęsek B, Okoń K, Darczuk D and Chomyszyn-Gajewska M: Evaluation of proinflammatory, NF-kappaB dependent cytokines: IL-1 $\alpha$, IL-6, IL-8, and TNF- $\alpha$ in tissue specimens and saliva of patients with oral squamous cell carcinoma and oral potentially malignant disorders. J Clin Med 9: 867, 2020.

37. Li L, Shen A, Chu J, Sferra TJ, Sankararaman S, Ke X, Chen Y and Peng J: Pien Tze Huang ameliorates DSS-induced colonic inflammation in a mouse colitis model through inhibition of the IL-6/STAT3 pathway. Mol Med Rep 18: 1113-1119, 2018.

38. Chen YY, Ma ZB, Xu HY, Shi LJ, Li DY, Sun LY, Yin XH, Sang GY, Xu D, Tang YH, et al: IL-6/STAT3/SOCS3 signaling pathway playing a regulatory role in ulcerative colitis carcinogenesis. Int J Clin Exp Med 8: 12009-12017, 2015.

39. Li Y, de Haar C, Chen M, Deuring J, Gerrits MM, Smits R, Xia B, Kuipers EJ and van der Woude CJ: Disease-related expression of the IL6/STAT3/SOCS3 signalling pathway in ulcerative colitis and ulcerative colitis-related carcinogenesis. Gut 59: 227-235, 2010.

40. Lee JS, Tato CM, Joyce-Shaikh B, Gulen MF, Cayatte C, Chen Y, Blumenschein WM, Judo M, Ayanoglu G, McClanahan TK, et al: Interleukin-23-Independent IL-17 production regulates intestinal epithelial permeability. Immunity 43: 727-738, 2015.

41. Zhang T, Zhang Z, Dong Q, Xiong J and Zhu B: Histone H3K27 acetylation is dispensable for enhancer activity in mouse embryonic stem cells. Genome Biol 21: 45, 2020. 